УДК: 159.9.07

\title{
СОЦИАЛЬНО-ПСИХОЛОГИЧЕСКИЕ АСПЕКТЫ КОМАНДООБРАЗОВАНИЯ В СОВРЕМЕННЫХ ОРГАНИЗАЦИЯХ
}

\author{
(C) 2020 Шакирьянова Алсу Илдаровна \\ кандидат экономических наук доцент \\ УВО «Университет управления «ТИСБИ», Россия, Казань \\ E-mail: alsu.shakiryanova@yandex.ru
}

(c) 2020 Ягудин Рамил Хаевич

доктор медицинских наук, кандидат экономических наук, доцент Высшей школы бизнеса

Казанский (Приволжский) федеральный университет, Россия, Казань

E-mail: RH65@mail.ru

(C) 2020 Желаева Дарья Игоревна

аспирант

ГБУ «Центр перспективных экономических исследований Академии наук Республики Татарстан»,

Россия, Казань

E-mail: dkananuha@mail.ru

В представленной статье в формате теоретического и критического подхода рассмотрены актуальные вопросы формирования корпоративной культуры и командообразования, а также рассмотрены, соответственно, возникающие в этом процессе практические проблемы. Уделено особое внимание командообразованию, мотивирующему на максимально плодотворную деятельность всех членов коллектива в организациях любой организационно-правовой формы. Показан процесс выявления лидера и постановки им задач по повышению эффективности и качества работы команды, направляющий ее на результативность и продуктивность. Приведены исследования о взаимосвязи эмоционального интеллекта и лидерства.

Ключевые слова: командообразование, мотивация, организация, организационная культура, тимбилдинг, лидер, руководитель, дебрифинг, тренинг.

Тема исследования обусловлена необходимостью изучения эмпирических данных в целях реализации аргументированных положений вопросов командообразования в реальной практике. Проблемы командообразования в научном поле освещены точечно и фрагментарно, поэтому актуальность не вызывает сомнения, так как в современном мире ее значение возрастает, ведь в каждой организации есть команда, которая сплочена одним делом, одной целью, что и ведет к успеху и дальнейшему устойчивому развитию.

В практике современного управления персоналом актуальны проблемы формирования организационной культуры, учитывающей особенности профессиональной деятельности. Эффективно действующая организационная культура способна решить ряд экономических и социальных проблем, снизить социальную напряженность в коллективе, формировать мотивацию персонала, развивать толерантность к самой организации, а также формировать положительный имидж организации в обществе.

Целенаправленное управление формированием и развитием организационной культуры любого учреждения позволяет сформировать новое деловое сообщество, объединенное признаками идентичности с единой целью и задачами.

Актуальность темы исследования подтверждается потребностью руководителей предприятий в ясном и четком определении понятия корпоративного духа организационной культуры, в практических рекомендациях по формированию и развитию корпоративного духа, его диагностике и оценке.

Составной частью организационной культуры является команда. Обзор специальной литературы позволяет оценить сложность и изучение методических инструментов, которые применять как при формировании, так и при работе в команде и с командой. На рисунке 1 
представлены определения понятий «команда» зарубежными авторами. Из отечественных авторов, можно выделить труды М.Литвака [7], где подробно раскрыты типы команд, методы работы в различных командах. Из представленных на рисунке 1 определений понятия «команда» видно, что все они разноплановые и часто понимаются субъектами управления по - разному, и, на наш взгляд, трактуются не всегда корректно.

Таким образом, команда в организации - это сплоченная группа людей, объединенных общей целью, решающих общие задачи, регламентированных заданными ролями. Построение команды, командообразование, или тимбилдинг (англ. Team building) представляет собой мероприятия, позволяющие наладить связи, сплотить сотрудников для выполнения единой задачи. Как подчеркивается экспертами, работа команда намного продуктивнее, чем работа отдельных участников. Мероприятия, способствующие формированию команды, могут быть такими же неформальными и случайными, как общая трапеза, или такими же формально структурированными, как сессия под руководством фасилитатора. К примеру, предлагается совместный выход на обед, на природу, участие в кейсах, празднование различных праздников и др. Актуально изречение Платона, о том, что за один час игры, можно узнать о человеке больше чем за один год общения.

Развивая это научное положение, важно помнить, что нужно консолидировать и интегрировать индивидуальные достижения ради общей победы. Дифференциация ролей в команде должна быть ярко выражена и заметна со стороны. И будут видны роль, значение и вклад каждого в достижение общей цели. Примерами настоящей команды могут служить: операционная команда, проектная команда, команда управления, спортивная команда (футбольная) и т.д.

Небольшой исторический ракурс. В 70-е годы

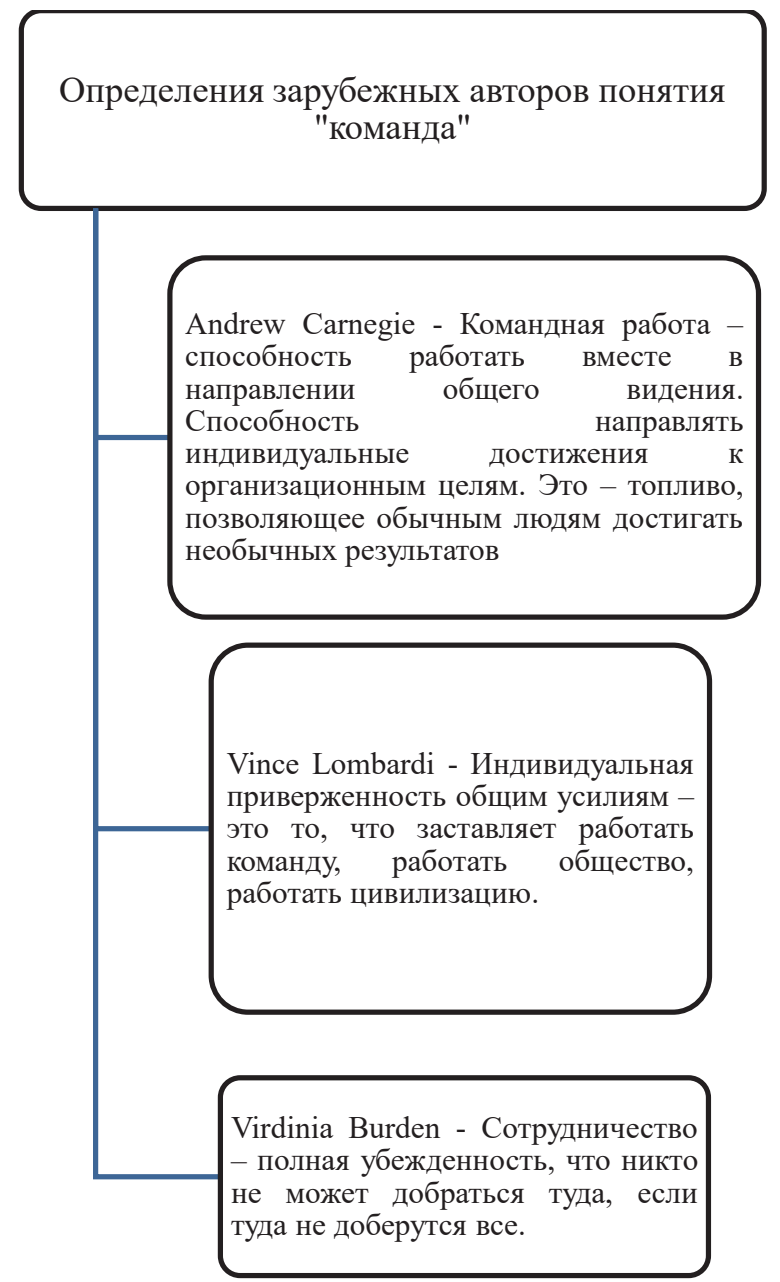

Рисунок 1. Анализ определений понятия «команда» [Источник: составлено автором]. 
прошлого столетия понятие «команда» было очень размытым, поэтому каждый трактовал и применял это понятие в рамках професиональной компетенции. По мнению исследователей Геллерт Манфреда и Новак Клауса [3] понятие команда было девальвировано: люди, которые просто работали вместе, не имея ничего общего, вдруг стали называться командой. При этом практически не стало существовать дифференциации между членами командами и их компетенциями, было нечеткое понятие о разумном распределении ролей, постановки целей и задачах руководства команды. Все вышеизложенное не позволяло достичь определенных высоких результатов коллективом. Сейчас же на практике мы имеем дело с командами, в которых по определению уже существует назначенное руководство, также в них включается профессиональный надзор [3].

Анализ классификации команд, приведенных на рисунке 2 свидетельствует о взаимном дополнении понятий друг другом, которые усиливают направленность на достижение успеха.

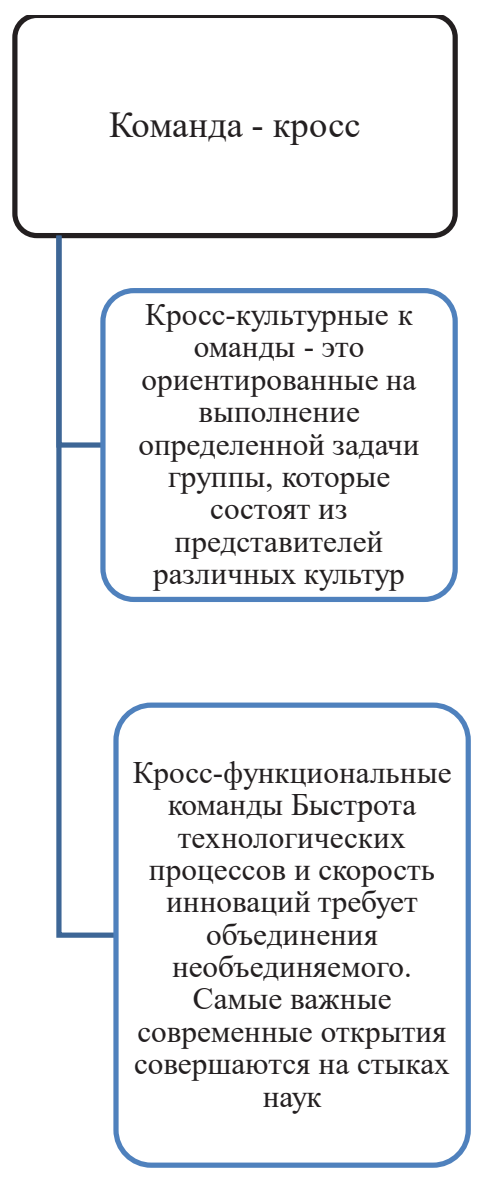

В условиях изменяющегося социальнопсихологического мира в поведенческой экономике важно и нужно разработать новый подход к формированию, развитию команды. Возникает острая необходимость уходить от понимания, и сущности которое было в 70-х годах. Поэтому сотрудники, которые испытывают потребность в неформальном общении, образуют именно группу, но не команду. Потому что у них нет интегрирующей, направленной вовне задачи. То, что они исполняют, в дальнейшем не синтезируется в единое целое. Нужна синергия для достижения нового, более высокого результата.

Исследователь Адизес Ицхак Калдерон [8] показал, что команды также могут распределяться на: кросс-культурные команды, кроссфункциональные команды, команды, созданные под проект, мультикоманды и т.д. Все эти разделения по-своему важны и имеют место в современном мире [8]. На рисунке 2 представлена классификация команд.

Что необходимо для создания и поддержания команды? Нами выявлено, что неотъемле-

Рисунок 2. Классификация команд [Источник: составлено автором] 
мой частью является регламентация контроля и обратная связь. Анализ научной литературы показал, что в зарубежной практике в большей степени развито применение ролевой функции тим-лидеров. Но, по мнению исследователей Доши Нил и Макгрегора Линдси роль тим-лидера очень важна в тимбилдинге [5]. Это - тот человек, который задает настрой команде, координирует ее и дает правильный вектор направления всей работы.

Впервые отметили эффективность применения принципов командообразования в силовых ведомствах, к примеру, в известной ЛосАламосской национальной лаборатории в США (место создания первой атомной бомбы) была создана организация Центр лидерства. Как отмечают эксперты, для специалиста необходимо владеть не только техническими знаниями, но и знать навыки управления персоналом. Но не всегда, заняв руководящую должность, сотрудник может применить инструменты и средства, которые использовались при выполнении индивидуальных задач и обеспечивали выполнение поставленных задач. При управлении командой эти методы не обеспечивают эффективного результата.

Командообразование коррелирует с наличием у сотрудников такой характеристики как эмоциональный интеллект. К примеру, представлены исследования, свидетельствующие о несомненной важности этой конструкции для корпоративного мира. Несомненно, интересным представляется исследование клинического психолога Рувена Бар-Он (Reuven Bar-On), которым впервые в 1988 г. применил понятие эмоционального интеллекта, предложил модель его расчета, предложил специальное обозначение $\mathrm{EQ}$ - emotional quotinent, применив аналогию с коэффициентом интеллекта IQ. «Множество не когнитивных способностей и навыков, влияющих на способность успешно справляться с требованиями и давлением окружения». В модели подсчета эмоционального интеллекта ученый определил следующие сферы компетентности, представленные на рисунке 3.

На основе вышеуказанных компонентов Р.Бар-Он разработал опросник для измерения эмоционального интеллекта, называющийся

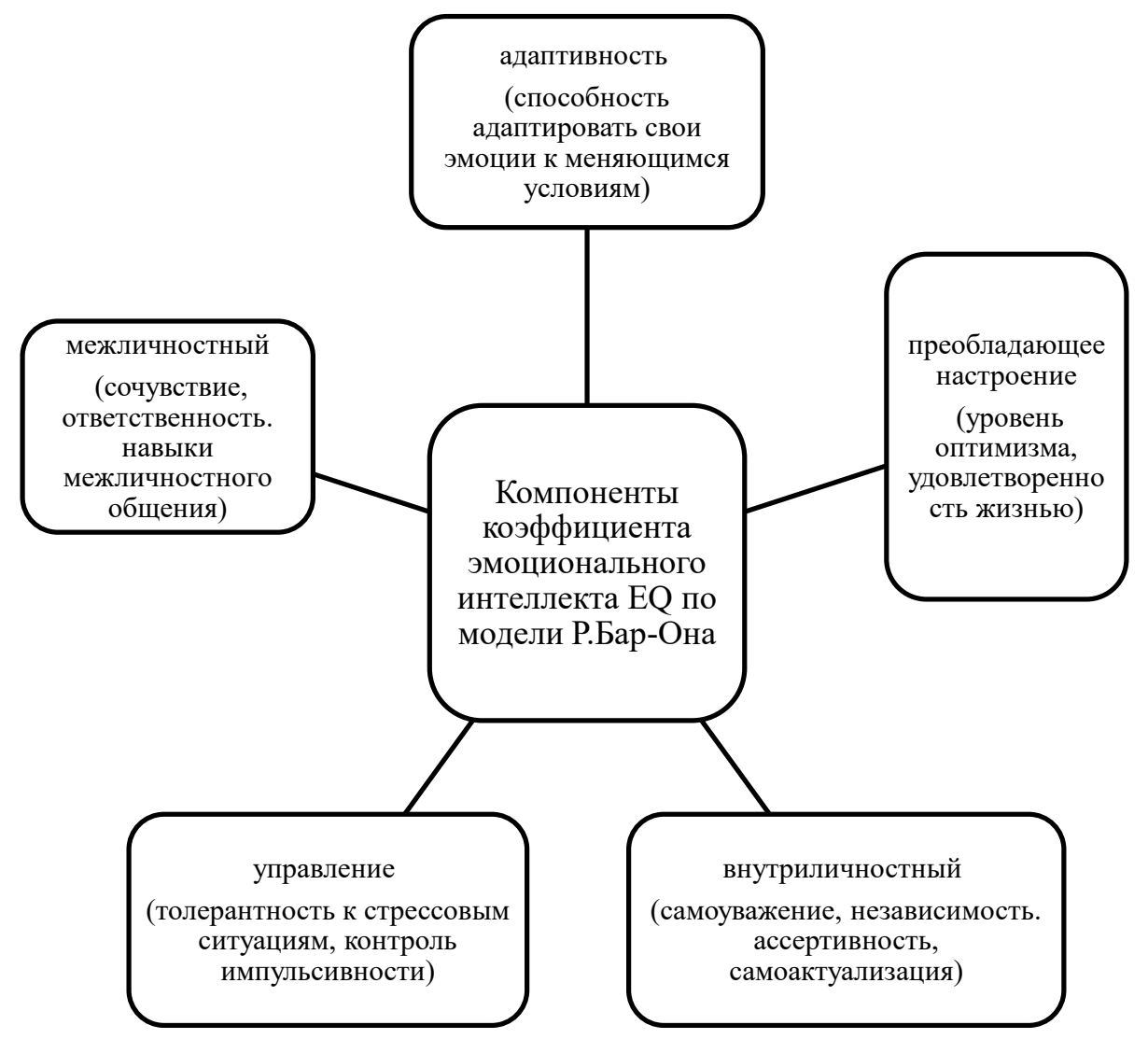

Рисунок 3. Структура коэффициента эмоционального интеллекта по модели Р.Бар-Она [Источник: составлено автором] 
EQ-i (Emotional Quotient Inventory).

В первом исследовании [Bar-On et al., 2006] 1096 мужчин- новобранцев израильских сил обороны (IDF) попросили «выбрать тех людей в вашем подразделении, которые наиболее подходят для руководящей роли». Тем, кто был идентифицирован своими сверстниками как обладающий лидерским потенциалом $(\mathrm{n}=536)$, было предложено пройти тест EQ-i. Общий балл за «лидерский потенциал» был рассчитан путем подсчета количества раз, когда рекрут был номинирован своими сверстниками за обладание этим конкретным атрибутом. Дискриминантный функциональный анализ был применен к данным, чтобы увидеть, могут ли баллы EQ-i различать рекрутов с самыми высокими и низкими оценками воспринимаемого сверстниками лидерского потенциала.

Результаты исследования показали, что действительно существует статистически значимая корреляция между эмоциональным интеллектом и лидерским потенциалом. Кроме того, полученные результаты показали, что модель эмоционального интеллекта, которая лучше всего идентифицирует лидерский потенциал в этой конкретной выборке включает эмоциональные и социальные факторы: самоуважение, эмпатия, стрессоустойчивость, адекватность восприятия мира и гибкость. Это означает, что те люди, которые обладали высоким уровнем этих конкретных факторов эмоционального интеллекта, воспринимались как обладающие высоким лидерским потенциалом.

Во втором исследовании клинического психолога Рувена Бар-Он уже 470 офицеров- стажеров израильских сил обороны (IDF) сравнивались со случайно выбранной группой из 470 новобранцев из той же выборки $(\mathrm{n}=2513)$. Считалось, что это представляет собой более надежный подход к выявление лидерского потенциала, и оно отличалось от подхода, использованного в предыдущем исследовании, поскольку группа новобранцев, которые фактически были зачислены на офицерскую подготовку, сравнивалась с группой новобранцев, которые не соответствовали минимальным требованиям к офицерской подготовке, к тому же участники группы не прошли необходимый психологический скрининг или не выразили желания быть офицерами. Оказалось, что средний балл у офицеров- стажеров был значительно выше, чем у рядовых:
108 против 100 соответственно (t=9,60, $\mathrm{p}<0,001)$. Далее был проведен дискриминантный анализ функций, позволяющий определить, насколько различаются исследуемые две группы. Результаты еще раз показали, что ЕI может предсказать лидерский потенциал и что эти две организации существенно связаны. Кроме того, лучшими предикторами эмоционального интеллекта и лидерства, по-видимому, являются следующие компетенции, навыки и фасилитаторы: самоуважение, эмоциональное самосознание, независимость, эмпатия, межличностные отношения, отношения, стрессоустойчивость, проверка реальности, решение проблем и счастье. На основе классификационной матрицы статистического приложения при использовании этой модели способность предсказывать лидерский потенциал составляет 69\% точности. Это означает, кроме того, что примерно 7 из 10 потенциально успешных кандидатов на офицерскую подготовку могут быть определены с помощью этой модели.

Одно из наиболее информативных исследований, изучавших взаимосвязь эмоционального интеллекта и лидерства, было проведено в Центре креативного лидерства (CCL) в Соединенных Штатах [Ruderman \& Bar-On, [2003]. В этом эпохальном исследовании 300 руководителей первоначально согласились принять участие, заполнив коэффициент EQ-i. Полные данные были получены для 236 участников после того, как из выборки были исключены четыре экстремальных выброса. В эту выборку вошли 175 мужчин и 61 женщина. Выборка состояла из руководителей из крупнейших организаций Северной Америки. Средний возраст составил 42,4 года для мужчин и 42,8 года для женщин. В дополнение к введению EQ-i для оценки EI, лидерские способности каждого человека оценивались в среднем семью - восемью коллегами с использованием бенчмарков. Ориентиры - это 360 Multi-оценщик степень разработан CCL, состоящий из 16 основных компонентов, предназначенных для оценки «успешного лидерства», и пяти компонентов, предназначенных для оценки «срыва», который является потенциалом для очень плохого лидерства. Рейтинги были объединены и усреднены, чтобы создать общий средний рейтинг для каждого участника. На основе анализа дискриминантных функций, который использовался для изучения влияния эмоционального интеллекта на лидерство, было обнаружено, что общая корреляция составила 0,74 , что означает, 
что по крайней мере 55\% успешного лидерства основано на эмоциональном интеллекте. Согласно этой модели, факторы эмоционального интеллекта наиболее сильное влияние лидерства оказывают эмпатия, межличностные отношения, социальная ответственность, стрессоустойчивость и умение решать проблемы. Интересно отметить, что первые три и самые сильные факторы - это те, которые часто называют «навыками общения с людьми», за которыми следует способность управлять эмоциями и решать проблемы [14].

В четвертом и последнем исследовании, Slaski и Cartwright [2002] изучили взаимосвязь между баллами EQ-i и несколькими различными аспектами лидерства среди 224 менеджеров среднего звена TESCO, которая является крупной британской розничной организацией. Управленческая эффективность оценивалась с использованием системы компетенций организации, которая включала 16 факторов, считающихся критическими для успеха, таких как способность ставить цели, планировать, организовывать и принимать решения. Исследователи также собирали данные об общем физическом и психологическом здоровье, а также субъективные показатели стресса. В дополнение к выявлению значительно высокой корреляции между эмоционального интеллекта и общей управленческой эффективности, было обнаружено, что более эмоционально интеллектуальные менеджеры испытывают значительно меньше стресса, здоровее и больше наслаждаются своей работой, когда по сравнению с менее эмоционально интеллектуальными менеджерами.

Охарактеризуем влияние эмоционального интеллекта на производительность организации. В новаторском исследовании, проведенном Лэнгхорном [2003] в Whitbread в Великобритании были обнаружены удивительные результаты, указывающие на определенную связь между эмоциональным интеллектом и организационной производительностью [14]. В частности, было установлено, что эмоциональный интеллект менеджеров ресторанов существенно влияет на ежегодный рост прибыли. Кроме того, на основании этого исследования факторами эмоционального интеллекта, которые являются лучшими предикторами продуктивности, являются эмоциональное самосознание, межличностные отношения, социальная ответственность, проверка реальности и счастье.
Было также обнаружено, что рестораны, управляемые менеджерами с высоким эмоциональным интеллектом, демонстрировали ежегодный рост прибыли на $22 \%$ по сравнению со средним годовым ростом на $15 \%$ за тот же период; это составило ежегодный рост для данной конкретной компании примерно на 110 мл фунтов стерлингов [14].

Было бы интересно поразмыслить над ежегодным ростом прибыли этих же ресторанов, если бы сотрудники, а также менеджеры смогли повысить свой эмоциональный интеллект в результате группового обучения и индивидуального коучинга, ориентированного на эти специфические факторы. А что, если это сочетается с подбором менеджеров ресторанов с эмоциональным самосознанием выше среднего, навыками межличностных отношений, социальной ответственностью, проверкой реальности и счастьем?

Как подойти к применению эмоционального интеллекта с целью максимизации организационной производительности. Существует семь ключевых способов, с помощью которых специалист по управлению персоналом может внедрить эмоциональный интеллект в комплекс мероприятий по управлению персоналом в конкретной организации. Некоторые из них будут более важными, чем другие, в зависимости от сферы деятельности организации.

1 Эквалайзер профилирование профессий и лучших сотрудников организации. Использование инструмента EQ позволяет создать организационное знание о том, что представляет собой исключительную производительность людей. Обычно это включает в себя проведение оценки эквалайзера как внутри, так и снаружи целевой группы менеджеров или индивидуумов. Использование профилирования обеспечивает прочную эмпирическую основу и надежный подход к отбору, обучению и планированию преемственности.

2 Набор и отбор - включает в себя использование оценки эмоционального интеллекта как части процессов отбора, используемых наряду с другими инструментами и методами оценки. Наиболее убедительные доказательства этого влияния можно найти в исследовании Хэнли, приведенном ранее в этой статье. Это основано в первую очередь о профилировании ЕI путем сравнения результатов EQ-i с профилем ЕI лучших сотрудников организации. 
3 Групповое обучение и развитие команды - Использование инструмента эмоционального интеллекта не только в рамках разработки вмешательства группового обучения или развития команды, но и в качестве самого вмешательства. Использование инструмента измерения эмоционального интеллекта стимулирует самосознание и обеспечивает очень важную отправную точку.

4 Индивидуальный корпоративный коучинг - или использование эмоционального интеллекта измерение в рамках индивидуального коучинга. Опыт экспертов показывает, что в большинстве случаев коучинг в организациях опирается на харизму личности (коуч и человек, которого тренируют), а не на профессиональные знания конкретной отрасли или предмета, науки.

5 Планирование преемственности включает в себя определение ключевой группы критически важных людей и разработку вмешательства эмоционального интеллекта, непо- средственно помогающего этой группе быть эффективной.

6 Применение эмоционального интеллекта в работе. Объяснив и проанализировав важность эмоционального интеллекта на рабочем месте, в этом разделе мы переключаем внимание на специалиста по управлению персоналом и вопрос о том, как можно локализовать, запустить и должным образом управлять эмоциональным интеллектом в рамках системы управления персоналом.

Исследователь Лора Стэк [2] установила, что дебрифинги являются частью становления команды, которая является важной частью, стержнем любого коллектива и той самой обратной нужной связью, необходимой для достижения успеха. Этот процесс помогает людям рассказать и показать не только свое эмоциональное состояние, но и рабочие моменты [2]. При обратной связи, благодаря высказанным мнениям каждого, приходит понимание, какие есть недоработки, проблемы в коллективе и перспективы

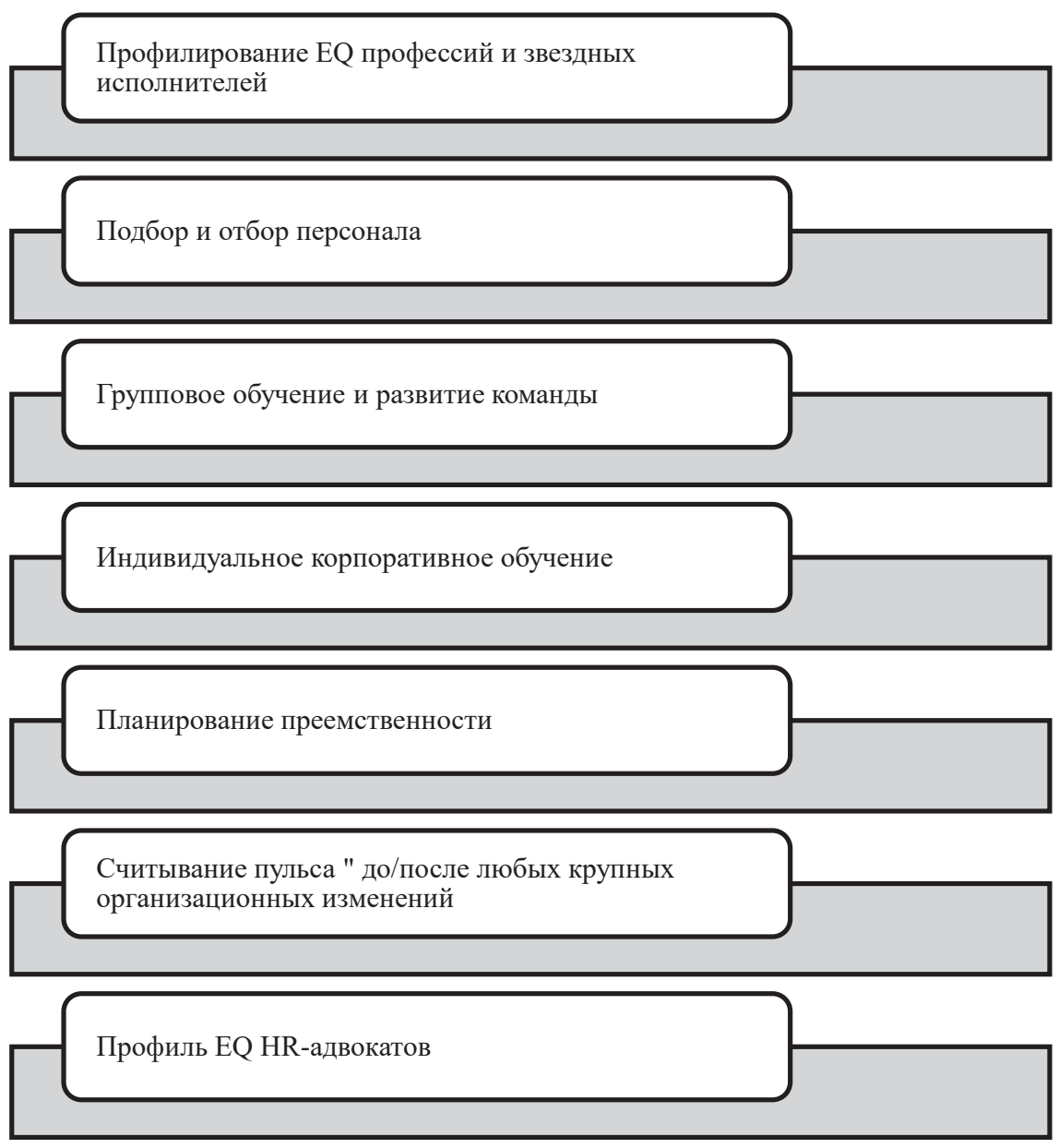

Рисунок 4. Методы развития эмоционального интеллекта в организации [18] 
развития. При создании новой группы, формировании и ее развитии можно воспользоваться различными играми на командообразование. Самым популярным является веревочный курс. С его помощью члены этой команды познакомятся, раскрепостятся и начнут доверять друг другу. В дальнейшем можно применять и другие практики в форме различных тренингов и других игр. Например, в трудах Клауса Фопеля «Создание команды. Психологические игры и упражнения» [11] приводится очень много разнообразных примеров для реализации программы с командой, где каждый может высказать свою точку зрения и проявить себя.

Таким образом, исходя из вышесказанного, нами сделан вывод, что командообразование это сложный процесс, требующий определенного времени. В первую очередь, это адаптация в коллективе, знакомство, привыкание и т.д. Чтобы этот этап шел продуктивнее и правильно, следует подобрать и назначить тим-лидера, и уже он будет проводить различные игры на командообразование, тренинги и корпоративы по сплочению и созданию здоровой нравственной атмосферы и комфортного психологического климата. Насколько эффективной будет работа в организации зависит от процесса командообразования. Ведь то какой будет работа и отношение в коллективе, такой будет и результат. А результат все хотят иметь всегда высокий.

\section{Библиографический список}

1. Бояцис Р. Э., Маки Э. На одной волне: Как управлять эмоциональным климатом в коллективе.- Альпина Паблишер. - 2017. 302с.

2. Вместе быстрее. 12 принципов командной эффективности: Лора Стэк; перевод с английского Наталии Брагиной.- Москва: Манн, Иванов и Фербер, 2018.- 265 с.

3. Все о командообразовании: руководство для тренеров: пер. с нем. / Манфред Геллерт, Клаус Новак.- Москва: Вершина, 2006. - 352 с.

4. Гандапас, Радислав Иванович. Харизма лидера.-4-е изд.- Москва: Манн, Иванов и Фербер, 2017. - 211 с.

5. Заряженные на результат: культура высокой эффективности на практике / Нил Доши и Линдси Макгрегор; перевод с английского Михаила Попова.-Москва: Манн, Иванов и Фербер, 2017. - 317 с.

6. Командос: как достигать больших целей вместе / Константин Борисов.- Москва: Альпина Паблишер, 2018. - 131 c.

7. Литвак M.Е. Командовать или подчиняться? // Изд-во «Феникс». - 2020. -380с.

8. Управление в эпоху кризиса: как сохранить ключевых людей и компанию / Ицхак Калдерон Адизес; пер. с англ. Т. Гутман.- Москва: Манн, Иванов и Фербер, 2015.- 149 с.

9. Фахрутдинова Е.В. Диалектика потребностей человека// Экономические науки. - 2009. - № 57._- С. $43-47$.

10. Фахрутдинова Е.В., Васильев А. К. Потребности и качество жизни человека: аспекты взаимодействия// Экономические науки. - 2009. - № 59.- С. 90-93.

11. Фопель К. Создание команды. Психологические игры и упражнения// Москва: Генезис. - 20003.-400с.

12. Bachman, J., Stein, S., Campbell, K., \& Sitarenios, G. (2000). Эмоциональный интеллект при взыскании долгов. International Journal of Selection and Assessment, 8 (3), 176-182.

13. Boyatzis, R. (1982). The competent manager: A model for effective performance. New York: John Wiley and Sons.

14. Goleman, D. (1998). Working with emotional intelligence. New York: Bantam.

15. Hay/McBer Research and Innovation Group (1997). This research was provided to Daniel Goleman and is reported in his book (Goleman, 1998).

16. Lusch, R. F., \& Serpkeuci, R. (1990). Personal differences, job tension, job outcomes, and store performance: A study of retail managers. Journal of Marketing.

17. Pesuric, A., \& Byham, W. (1996, July). The new look in behavior modeling. Training and Development, 25-33.

18. Spencer, L. M. J., McClelland, D. C., \& Kelner, S. (1997). Competency assessment methods: History and state of the art. Boston: Hay/McBer.

19. Walter V. Clarke Associates. (1996). Activity vector analysis: Some applications to the concept of emotional intelligence. Pittsburgh, PA: Walter V. Clarke Associates. 